\title{
Role of the Rho/ROCK signaling pathway in the protective effects of fasudil against acute lung injury in septic rats
}

\author{
YU WANG, XIAOFENG WANG, WEI LIU and LICHUN ZHANG
}

Emergency Department, Shengjing Hospital Affiliated to China Medical University, Shenyang, Liaoning 110004, P.R. China

Received February 1, 2018; Accepted August 13, 2018

DOI: $10.3892 / \mathrm{mmr} .2018 .9446$

\begin{abstract}
Fasudil, which is primarily prescribed to treat cerebral vasospasm, may also inhibit systemic inflammation and prevent sepsis-induced acute lung injury (ALI) in rats, although the mechanisms remain elusive. The purpose of the present study was to investigate the role of the rhodopsin (Rho)/Rho-associated protein kinase (ROCK) signaling pathway in the protective effects of fasudil on ALI in septic rats. A total of 60 Wistar rats were pretreated with fasudil $(30 \mathrm{mg} / \mathrm{kg}$ ) through intraperitoneal injections $1 \mathrm{~h}$ prior to cecal ligation and puncture. Administration of fasudil led to reductions in polymorphonuclear neutrophil counts, and the protein concentrations of tumor necrosis factor- $\alpha$, interleukin (IL)-1 $\beta$ and IL-6 in the bronchoalveolar lavage fluid of rats with sepsis-induced ALI. The results demonstrated that fasudil decreased sepsis-induced bacteremia. In addition, fasudil effectively reduced the Evans blue content, wet/dry lung weight ratio, lung injury score, and expression levels of malondialdehyde and myeloperoxidase. However, the superoxide dismutase activity in the lung tissue of the rats was increased. Activated caspase-3 activity in lung tissue was reduced to $29 \%$ by fasudil. Furthermore, the expression of Rho and ROCK1 was significantly downregulated, and the phosphorylation of myosin phosphatase-targeting subunit 1 in lung tissues was markedly decreased, whereas the protein expression levels of zonula occludens 1 were increased in fasudil-treated rats $(\mathrm{P}<0.05)$. In the in vitro experiments, vascular endothelial growth factor, intracellular adhesion molecule 1 and vascular cell adhesion molecule 1 secreted from human pulmonary microvascular endothelial cells treated with lipopolysaccharide (LPS) were attenuated by fasudil. Fasudil also reduced the fluorescence intensity of filamentous actin induced by LPS. Taken together, the results of the present study demonstrated that fasudil was able to improve endothelial permeability and
\end{abstract}

Correspondence to: $\mathrm{Dr} \mathrm{Yu}$ Wang, Emergency Department, Shengjing Hospital Affiliated to China Medical University, 36 Sanhao Street, Heping, Shenyang, Liaoning 110004, P.R. China E-mail: wangy8@sj-hospital.org

Key words: fasudil, sepsis, acute lung injury, rhodopsin, Rho-associated protein kinase, zonula occludens 1 inhibit inflammation, oxidative stress and cellular apoptosis in order to alleviate ALI in septic rats through inhibition of the Rho/ROCK signaling pathway.

\section{Introduction}

Sepsis, which is caused by the maladjustment of a host response to infection, may culminate in fatal organ dysfunction, and has a high mortality rate. The lung is the most vulnerable target organ among the multiple organ injuries associated with sepsis, and acute lung injury (ALI) is also one of the important causes of sepsis-associated mortality, due to its early occurrence and high incidence rate (1). This has led to the requirement for a more in-depth understanding of sepsis pathogenesis, as the majority of therapeutic approaches have failed to decrease mortality from severe sepsis. A previous study reported that endothelial damage leads to neutrophil aggregation, inflammatory responses and oxidative stress, which ultimately leads to lung injury (2). Therefore, it is essential to understand the pathogenesis of lung injury in order for novel and effective therapeutic targets to be identified.

Rhodopsin (Rho) is among the most well-characterized downstream effectors of the Rho family of small GTPases. The Rho/Rho-associated protein kinase (ROCK) signaling peptide, with signal transduction and molecular switching effects, regulates endothelial cell permeability via endothelial cell cytoskeleton remodeling (3). Previous studies have indicated that the Rho/ROCK signaling pathway serves an important role in the pathogenesis of sepsis-induced pulmonary epithelial permeability increases (4).

Fasudil is principally used to treat cerebral vasospasm and improve brain microcirculation clinically. The present study demonstrated that, as a specific Rho inhibitor, fasudil has a wide range of pharmacological effects, including as a vasodilator and as an anti-inflammatory, by inhibiting Rho/ROCK to influence a variety of cellular functions. It has been reported that fasudil inhibits systemic inflammation and guards against ALI in septic mice (5); however, the data were not fully conclusive and it is necessary to have an improved understanding of how fasudil achieved these beneficial effects through modulation of the inflammatory response in the murine model. In the present study, a sepsis model was established in rats using cecal ligation and puncture (CLP), and the effects of fasudil on the Rho/ROCK signaling pathway and endothelial cell permeability in sepsis-induced ALI were investigated. 


\section{Materials and methods}

Experimental animals. Specific pathogen-free, 8-week old male Wistar rats $(220 \pm 20 \mathrm{~g})$ used in the present study were obtained from the Experimental Animal Center of the Chinese Academy of Medical Sciences (Beijing, China). Animals received food and water ad libitum during 1 week of acclimation. Rats were kept under a 12 -h light/dark cycle at $22-25^{\circ} \mathrm{C}$ and $60 \%$ relative humidity. All experimental protocols were conducted with the approval of the Medical Research and New Technology Ethics Committee of Shengjing Hospital affiliated to China Medical University.

Rat sepsis model. Polymicrobial sepsis in rats was induced by CLP as described previously (6). In brief, the rats were anesthetized using $5 \%$ chloral hydrate $(300 \mathrm{mg} / \mathrm{kg})$ via intraperitoneal injection and a $2 \mathrm{~cm}$-long incision was made along the midline of the anterior abdomen. The cecum was gently exposed and ligated at $\sim 50 \%$ of the total length with a 5-0 silk suture. On the antimesenteric side, the cecum was punctured twice with an 18-gauge needle. A small amount of feces was squeezed out from both ends of the perforation. Following this, the cecum was repositioned and the abdomen was closed. Rats in the sham-operated group had an identical laparotomy performed; however, the cecum was neither ligated nor perforated.

Animal groups. A total of 60 Wistar rats were randomized into the following three groups: A sham-operated group, a CLP (sepsis) group and a CLP + fasudil (treatment) group, with 20 rats in each group. The treatment groups received intraperitoneal injections of fasudil $30 \mathrm{mg} / \mathrm{kg}$ (Sigma-Aldrich; Merck KGaA, Darmstadt, Germany) 1 h prior to surgery. The sham-operated and sepsis groups were treated with an equal amount of sterile saline by intraperitoneal injection. In all groups, the following experiments were performed at $24 \mathrm{~h}$ following the CLP procedure.

Monitoring of hemodynamics. At $24 \mathrm{~h}$ following surgery, the rats were again anesthetized with $5 \%$ chloral hydrate $(300 \mathrm{mg} / \mathrm{kg}$ ) by intraperitoneal injection. When the right carotid artery had been exposed, a catheter was plunged in the right common carotid artery, and the mean arterial pressure (MAP) was measured with an RM6240BD multichannel physiological signal acquisition and processing system (Chengdu Instrument Factory, Chengdu, China).

Bacterial cultures. At $24 \mathrm{~h}$ following CLP, blood samples were drawn from the inferior vena cava and cultured to evaluate the bacterial clearance. Serial logarithmic diluted blood was plated on trypticase soy agar II (BD Biosciences, Franklin Lakes, NJ, USA) with 5\% sheep blood (BD Biosciences, Franklin Lakes, NJ, USA). Plates were incubated under aerobic conditions at $37^{\circ} \mathrm{C}$, and the colonies were calculated after $24 \mathrm{~h}$ of incubation. Bacterial counts are expressed as the number of colony-forming units $\left(\mathrm{x} 10^{5}\right)$ per milliliter of blood.

Detection of serum biochemical indexes. Blood samples were collected from the inferior vena cava (1:10 acid citrate dextrose) and centrifuged at $10,010 \mathrm{x}$ g for $10 \mathrm{~min}$ at $4^{\circ} \mathrm{C}$. The supernatant was collected and stored at $-20^{\circ} \mathrm{C}$. Then, $1 \mathrm{ml}$ of supernatant was taken to detect the serum alanine aminotransferase (ALT), aspartate aminotransferase (AST), blood urea nitrogen (BUN) and creatinine $(\mathrm{Cr})$ levels in rats, and the whole process was completed by the Roche cobas- 8000 automatic biochemical analyzer (Roche Diagnostics, Basel, Switzerland) provided by the laboratory department of the Shengjing Hospital affiliated to China Medical University.

Detection of endothelial cell permeability (7). A total of 8 rats in each group were injected with Evans blue (EB; $20 \mathrm{mg} / \mathrm{kg}$, Sigma-Aldrich; Merck KGaA) through the tail vein. After $30 \mathrm{~min}$, the rats were sacrificed and the left lungs were collected. The left lung tissue was homogenized with formamide and incubated at $37^{\circ} \mathrm{C}$ for $18 \mathrm{~h}$, following which the homogenate was centrifuged at $8,000 \mathrm{x} \mathrm{g}$ for $10 \mathrm{mins}$ at $4^{\circ} \mathrm{C}$. The absorbance (A) of the supernatant was measured at $620 \mathrm{~nm}$ with a spectrophotometer, and the amount of EB in the lung tissue was calculated.

Determination of bronchoalveolar lavage fluid (BALF). The remaining rats in each group were sacrificed $24 \mathrm{~h}$ following CLP and a tracheal intubation was performed upon separating the trachea and the main bronchus. The left lung was washed three times with $0.5 \mathrm{ml}$ pre-cooled PBS. The BALF was centrifuged for $10 \mathrm{~min}$ at $1,500 \mathrm{x} \mathrm{g}$ at $4^{\circ} \mathrm{C}$. The protein concentrations in the BALF were detected using a protein quantification kit (Bio-Rad Laboratories, Inc., Hercules, CA, USA), according to the manufacturer's protocol. The levels of TNF- $\alpha$ (cat. no. ab208348), IL-1 $\beta$ (cat. no. ab100704) and IL-6 (cat. no. ab100712) in the BALF were determined using ELISA kits (Abcam, Cambridge, UK). The TNF- $\alpha$, IL- $1 \beta$ and IL- 6 content in the samples was calculated using a standard calibration curve. The detection ranges of the TNF- $\alpha$, IL-1 $\beta$ and IL-6 ELISA assays were 12.5-800, 31.25-2,000 and 62.5-4,000 pg/ml, respectively. Concentrations of samples that were initially over the limit of the standard curve were measured following dilution.

The BALF cells were resuspended with PBS, and a small number of the suspended cells were dropped onto a slide. Following Wright-Giemsa staining for $10 \mathrm{~min}$ at room temperature, polymorphonuclear neutrophils (PMN) were counted using an Eclipse E200 optical microscope (Nikon Corporation, Tokyo, Japan) under a high-power field (magnification, $\mathrm{x} 400$ ). A total of five randomly selected non-overlapping fields on each slide were observed.

Determination of oxidative stress in lung tissue. Right lung tissue was collected, and the lung homogenate was centrifuged for $15 \mathrm{~min}$ at $15,000 \mathrm{x} \mathrm{g}$ at $4^{\circ} \mathrm{C}$. Malondialdehyde (MDA; cat. no. A003-1) levels were detected using the thiobarbituric acid colorimetric method, superoxide dismutase (SOD; cat. no. A001-3) was determined by the yellow purine oxidase method and myeloperoxidase (MPO; cat. no. A044) was determined in the supernatant by tetramethylbenzidine method, using kits from Nanjing Jiancheng Bioengineering Institute, Nanjing, China in strict accordance with the manufacturer's protocol.

Wet/dry (W/D) lung weight ratios. The right upper lung was collected and weighed (W) when the water and blood on the 
surface had been removed with filter paper. The lung tissue was subsequently placed in an $80^{\circ} \mathrm{C}$ dryer for $24 \mathrm{~h}$, and weighed again (D). The W/D ratio of the lung tissue was calculated.

Lung tissue histological evaluations. Rat lung tissues were fixed in $4 \%$ paraformaldehyde for $48 \mathrm{~h}$ at $4^{\circ} \mathrm{C}$, and the specimens were dehydrated, embedded in paraffin, sectioned at $5 \mu \mathrm{m}$ and stained with hematoxylin and eosin for $10 \mathrm{~min}$ at room temperature. Subsequently, the pathological alterations in the lung tissue were examined under an optical microscope. A scoring system was used to assess the degree of lung injury based on the following histological features: Edema; hyperemia and congestion; neutrophil margination and tissue infiltration; intra-alveolar hemorrhage and debris; and cellular hyperplasia. These characteristics were subjectively scored on a scale between 0 and 3: 0 , normal; 1 , slight effect; 2 , moderate presence of that feature; and 3, severe effect. A total score was calculated for each rat (8). A total of 6 slides were randomly selected from each group. At least 10 high-power fields were captured per well (magnification, $\mathrm{x} 400$ ). The lung injury scores were evaluated by an independent pathologist to objectively quantify the degree of lung injury.

Detection of caspase-3 activity in lung tissue. Caspase-3 protease activity in the lung tissue was determined using a caspase-3 colorimetric assay kit (Sigma-Aldrich; Merck $\mathrm{KGaA}$ ), in accordance with the manufacturer's protocol. In brief, following homogenization of the whole lung tissue in cell lysis buffer, homogenates were centrifuged for $1 \mathrm{~min}$ at $10,000 \times \mathrm{g}$, and the supernatant was extracted and incubated with Asp-Glu-Val-Asp-p-nitroanilide (pNA) and reaction buffer for $90 \mathrm{~min}$ at $37^{\circ} \mathrm{C}$. Levels of the chromophore pNA were quantified using a spectrophotometer at $405 \mathrm{~nm}$, which reflected the caspase- 3 activity. The data were normalized to the lung weight.

Activity of the Rho/ROCK signaling pathway and expression of zonula occludens 1 (ZO-1). Proteins were extracted from the lung tissue using a commercial Protein Extraction kit (Nanjing Keygen Biotech Co., Ltd., Nanjing, China), according to the manufacturer's protocol. Protein concentrations were quantified using a bicinchoninic acid assay kit (Beyotime Institute of Biotechnology, Haimen, China). Equal amounts of protein loading per well were separated by SDS-PAGE on $10 \%$ gels and transferred to polyvinylidene fluoride membranes (EMD Millipore, Billerica, MA, USA). The membranes were blocked with $5 \%$ skimmed milk for $1 \mathrm{~h}$ at room temperature, and subsequently incubated with primary antibodies [rabbit monoclonal anti-Rho (cat. no. ab40673; 1:500), monoclonal anti-ROCKl (cat. no. ab4517; 1:500; both Abcam) or rabbit monoclonal anti-myosin phosphatase targeting subunit 1 (MYPT-1; cat. no. 8574; 1:1,000), monoclonal anti-phosphorylated (p)-MYPT-1 (cat. no. 4563; 1:1,000; both Cell Signaling Technology, Inc., Danvers, MA, USA) or rabbit monoclonal anti-ZO-1 (cat. no. 14-9776-82; 1:1,000; Invitrogen; Thermo Fisher Scientific, Inc., Waltham, MA, USA) or $\beta$-actin (cat. no. ARE6011; 1:1,000; Hangzhou HuaAn Biotechnology Co. Ltd., Hangzhou, China) at $4^{\circ} \mathrm{C}$ overnight. The membranes were subsequently incubated with horseradish peroxidase-conjugated goat anti-rabbit secondary antibody (cat. no. A9298; 1:1,000; Beyotime Institute of Biotechnology) at $37^{\circ} \mathrm{C}$ for $45 \mathrm{~min}$. An enhanced chemiluminescence imaging system (Bio-Rad Laboratories, Inc., Hercules, CA, USA) was used to visualize the protein bands. The ratio of p-MYPT-1 expression to MYPT-1 expression reflected the level of MYPT-1 phosphorylation. Image $\mathbf{J}$ version, $1.51 \mathrm{~h}$ (National Institutes of Health, Bethesda, MD, USA) was used for image analysis.

Cell strain. Human pulmonary microvascular endothelial cells (HPMVEC-ST1.6R) were purchased from Clonetics ${ }^{\mathrm{TM}}$ (Lonza Group Ltd., Basel, Switzerland). Cells were cultured in $10 \mathrm{~cm}$ plates and maintained in Dulbecco's modified Eagle's medium supplemented with $10 \%$ fetal bovine serum (both Gibco; Thermo Fisher Scientific, Inc.) in a $37^{\circ} \mathrm{C}$ humidified incubator with $5 \% \mathrm{CO}_{2}$. The medium was changed every 2 days. When the cells grew to $80-90 \%$ confluence, they were digested and subcultured with $0.25 \%$ EDTA-trypsin, and the fourth passage of endothelial cells were used for subsequent experimentation.

MTT assay for cell viability. The cytotoxic effects of lipopolysaccharide (LPS) on HPMVEC-ST1.6R were assessed using an MTT assay (9). The HPMVEC-ST1.6R were inoculated in 96-well culture plates $\left(5 \times 10^{4}\right.$ cells/well in $100 \mu 1$ medium), and the cells were exposed to varying concentrations $(0,0.01$, $0.1,1,10$ and $100 \mu \mathrm{g} / \mathrm{ml}$ ) of LPS and incubated for $24 \mathrm{~h}$ when the cells had adhered. Each well was treated with $10 \mu \mathrm{l}$ of $0.5 \mathrm{mg} / \mathrm{ml} \mathrm{MTT}$ at the end of the incubation. The plate was placed in a $37^{\circ} \mathrm{C}$ humidified incubator for an additional $4 \mathrm{~h}$, the supernatant was discarded, and $200 \mu \mathrm{l}$ dimethyl sulfoxide was added to each well. The absorbance was measured at $490 \mathrm{~nm}$ using a BioTek MQX 680 (BioTek Instruments, Inc., Winooski VT, USA).

In order to observe the effects of fasudil on LPS-induced HPMVEC-ST1.6R injury, the synchronized cells were randomly divided into a control group, a $24 \mathrm{~h}$ LPS $(10 \mu \mathrm{g} / \mathrm{ml})$ treatment group and fasudil $(10,25$ and $50 \mathrm{mM})$ pretreatment groups. Synchronized cells were pretreated with different concentrations of fasudil for $2 \mathrm{~h}$, and subsequently treated with $10 \mu \mathrm{g} / \mathrm{ml}$ LPS for $24 \mathrm{~h}$. The determination method was the same as the MTT assay protocol described above.

Quantitative analysis of vascular endothelial growth factor (VEGF), intercellular adhesion molecule-1 (ICAM-1) and vascular cell adhesion molecule-1 (VCAM-1) production in endothelial cells. HPMVEC-ST1.6R were respectively pre-incubated with fasudil at different concentrations $(10,25$ and $50 \mu \mathrm{M})$ for $30 \mathrm{~min}$, following which $10 \mu \mathrm{g} / \mathrm{ml}$ LPS was added to supernatant in each well $\left(1 \times 10^{5}\right.$ cells $\left./ \mathrm{ml}\right)$ and reacted for $24 \mathrm{~h}$. The quantitative analysis of VEGF (cat. no. ab100751), ICAM-1 (cat. no. ab100688) and VCAM-1 (cat. no. ab100750) in endothelial cell supernatants was performed via ELISA (Abcam), according to the manufacturer's protocol.

Effects of different concentrations of fasudil on the HPMVEC-ST1.6R skeletal structural alterations induced by $L P S$. Synchronized cells were randomly divided into a control group, LPS $(10 \mu \mathrm{g} / \mathrm{ml})$ treatment group and fasudil $(50 \mathrm{mM})$ 

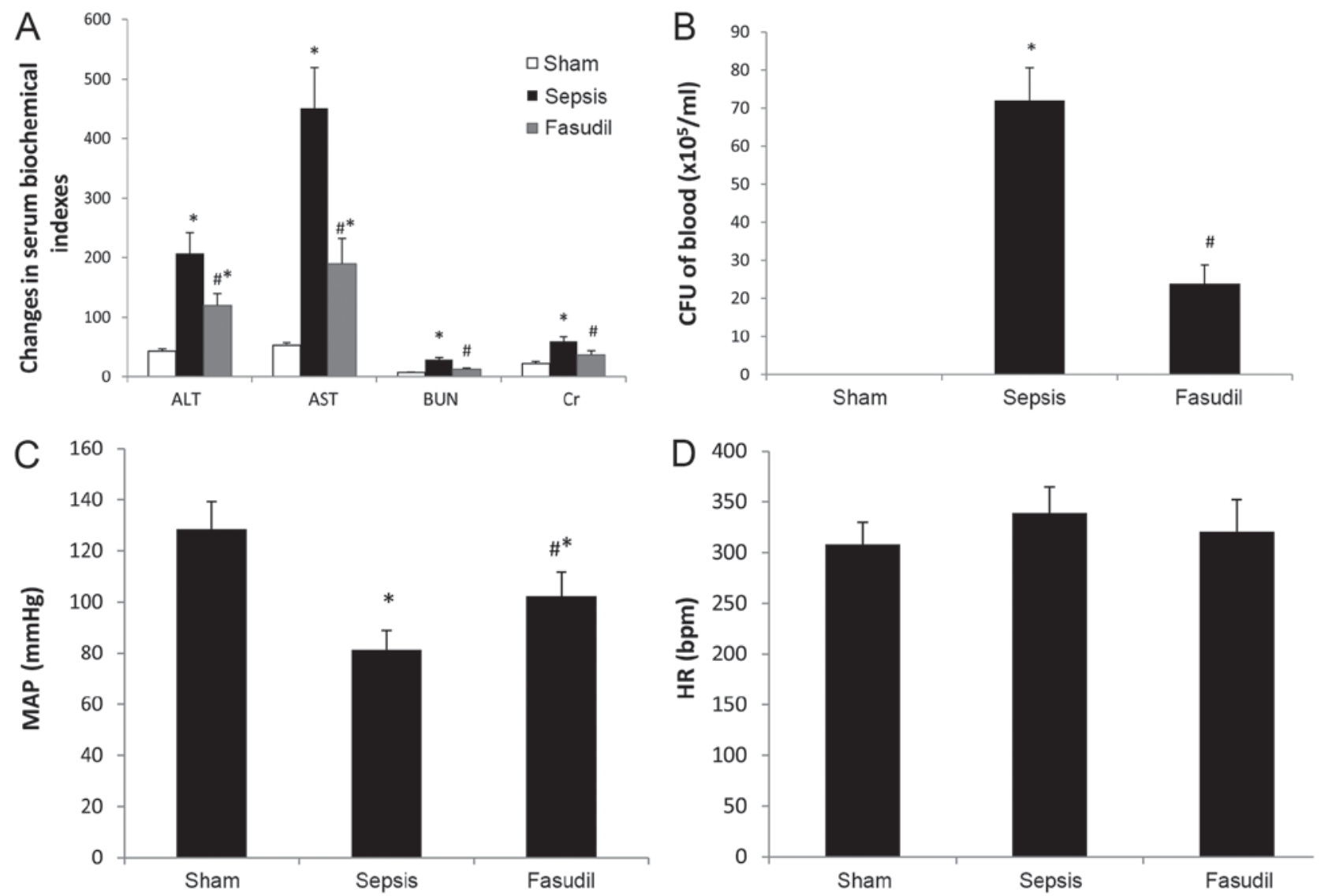

Figure 1. Effect of fasudil on serum biochemical indexes, systemic bacteremia and hemodynamics in rats with sepsis-induced ALI. (A) Fasudil decreased the serum levels of ALT, AST, BUN and Cr in rats with sepsis-induced ALI. (B) Fasudil decreased the number of bacteria in the blood in rats with sepsis-induced ALI. (C) Fasudil increased the MAP in rats with sepsis-induced ALI. (D) HR in the three groups. Data are expressed as the mean \pm standard deviation. $n=10$. ${ }^{*} \mathrm{P}<0.05$ vs. Sham; ${ }^{\#} \mathrm{P}<0.05$ vs. Sepsis. ALI, acute lung injury; ALT, alanine aminotransferase; AST, aspartate aminotransferase, BUN, blood urea nitrogen; Cr, creatinine; $\mathrm{CFU}$, colony-forming units; MAP, mean arterial pressure; HR, heart rate.

pretreatment group. Synchronized cells were pretreated with different concentrations of fasudil for $2 \mathrm{~h}$, and subsequently treated with $10 \mu \mathrm{g} / \mathrm{ml}$ LPS for $24 \mathrm{~h}$. The cells were fixed with $4 \%$ paraformaldehyde for $30 \mathrm{~min}$ at room temperature and washed with PBS solution three times. Subsequently, the cells were permeabilized with $0.2 \%$ Triton X-100 for $30 \mathrm{~min}$ at room temperature. Subsequently, $10 \%$ goat serum (cat. no. 50062Z; Invitrogen; Thermo Fisher Scientific, Inc.) was used for blocking for $30 \mathrm{~min}$ at room temperature following washing with PBS. The Fluorescein isothiocyanate (FITC)-conjugated phalloidin $(1: 1,000)$ was added to the cells at $4^{\circ} \mathrm{C}$ overnight. The nuclei were re-stained with DAPI and incubated at room temperature without light for $10 \mathrm{~min}$. The different groups were detected using a Leica SP2 laser confocal microscope (magnification, x600; Leica Microsystems GmbH, Wetzlar, Germany). Filamentous (F-)actin expression abundance was determined by the intensity of cellular fluorescence.

Data analysis. SPSS 18.0 software (SPSS, Inc., Chicago, IL, USA) was used for statistical analysis. Measurement data are expressed as the mean \pm standard deviation. One-way analysis of variance followed by Tukey's test was used to analyze the differences among groups. $\mathrm{P}<0.05$ was considered to indicate a statistically significant difference. The experiments were repeated independently $>3$ times.

\section{Results}

Experimental model and mortality. A total of $24 \mathrm{~h}$ following CLP, the rats presented with reduced activity, erect hair, shivering, fatigue, exudation around the eyes, dyspnea and tachycardia. The rats were unresponsive to external stimuli and exhibited hematuria, pyuria and diarrhea. The laparotomy revealed bloody ascites with an odor, swelling and necrosis at the cecal ligation site, in addition to whole abdominal adhesion and severe inflation of the small intestine, with visceral congestion and edema. Conversely, in the fasudil group, the general health of the rats was improved. A laparotomy revealed a reduction in the number of ascites and the level of necrosis. Adhesions were observed only at the cecal ligation site, and the abscess was confined to the area surrounding the cecum, and the expansion of the small intestine was less severe. Rats in the CLP group exhibited a survival rate of $83.3 \%$ (10 survivals in 12 rats) at $24 \mathrm{~h}$, while the survival rate of the fasudil group was 91.7\% (11 survivals in 12 rats), which was higher compared with that of the sepsis group; however, there were no statistically significant differences in the survival rates between the two groups (Data not shown). Compared with the sham-operated group, the serum levels of ALT, AST, BUN and Cr in the sepsis group and fasudil group were all increased. Compared with the sepsis group, the serum levels of ALT, AST, BUN and $\mathrm{Cr}$ in the fasudil group were all decreased $(\mathrm{P}<0.05 ; \mathrm{n}=10 ;$ Fig. 1A). 

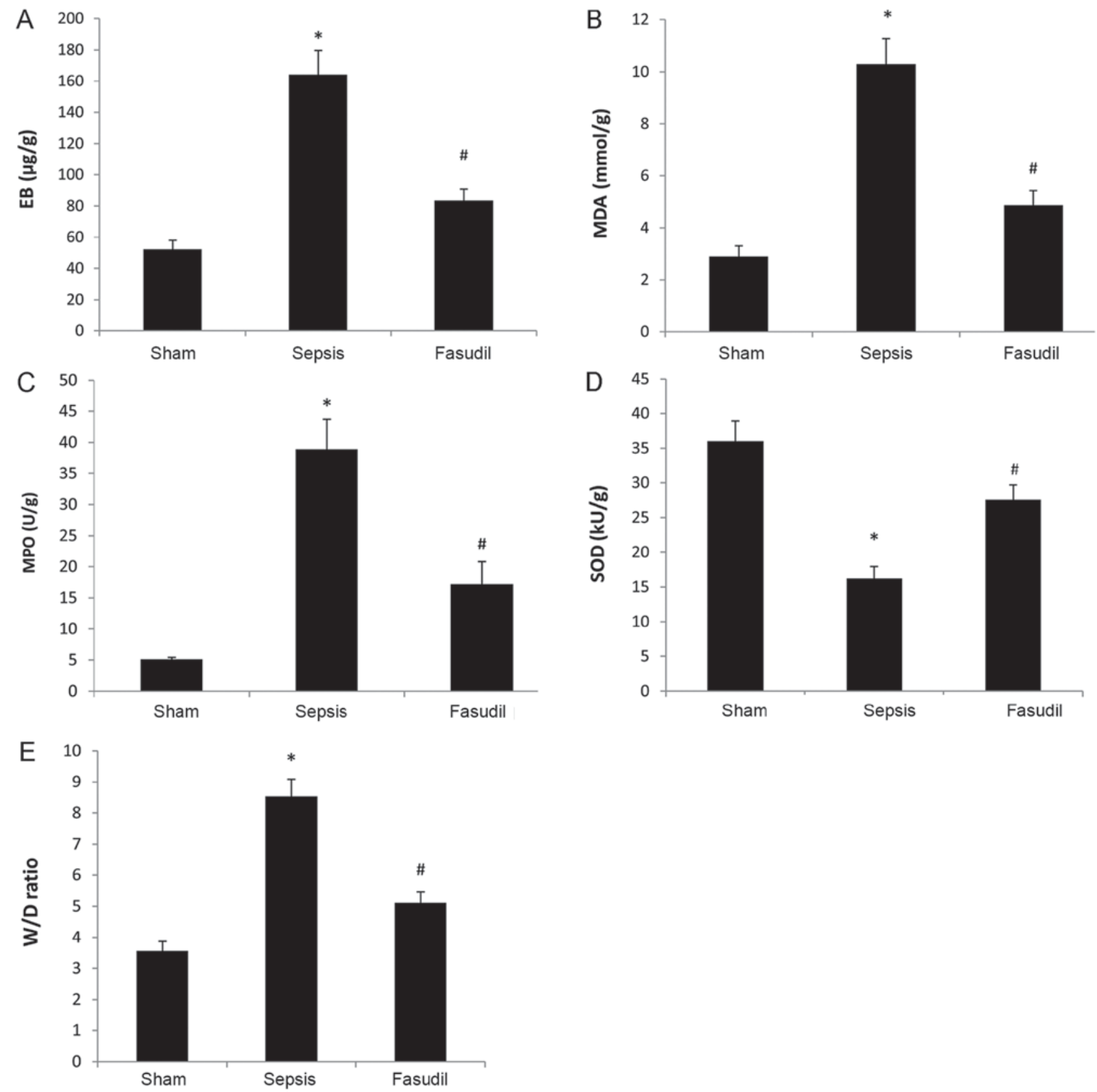

Figure 2. Effect of fasudil on endothelial cell permeability, the levels of oxidative stress and lung edema in rats with sepsis-induced ALI. (A) Fasudil improved lung endothelial cell permeability in rats with sepsis-induced ALI. Fasudil decreased the levels of (B) MDA and (C) MPO, and (D) increased the activity of SOD in rats with sepsis-induced ALI. (E) Fasudil reduced the lung W/D ratio in rats with sepsis-induced ALI. Data are expressed as the mean \pm standard deviation. $\mathrm{n}=10$. "P<0.05 vs. Sham; $\mathrm{P}<0.05$ vs. Sepsis. ALI, acute lung injury; MDA, malondialdehyde, MPO, myeloperoxidase; SOD, superoxide dismutase; W/D, wet/dry weight; EB, Evans blue.

Systemic bacteremia. The number of bacteria in the blood from the sepsis group was markedly higher compared with that from the sham-operated group. However, the number of bacteria in the blood from the fasudil group was significantly lower compared with that from the sepsis group $(\mathrm{P}<0.05$; $\mathrm{n}=10$; Fig. 1B).

Hemodynamic analysis. MAP was significantly increased in the fasudil group compared with the sepsis group $(\mathrm{P}<0.05)$, whereas the differences in heart rate between the three groups were not statistically significant $(\mathrm{P}>0.05$; $\mathrm{n}=10$; Fig. $1 \mathrm{C}$ and D).
Permeability of lung endothelial cells. The EB content in the lung tissue from the sepsis group was significantly increased compared with the sham-operated group, whereas the EB content in the fasudil group was significantly reduced compared with the sepsis group $(\mathrm{P}<0.05 ; \mathrm{n}=10$; Fig. $2 \mathrm{~A})$.

Oxidative stress indexes in lung tissue. Levels of MDA and MPO in lung tissues from the sepsis group were significantly increased compared with the sham-operated group; however, the activity of SOD was significantly reduced. Conversely, the levels of MDA and MPO in lung tissues from the fasudil group were significantly lower compared with those from the sepsis 

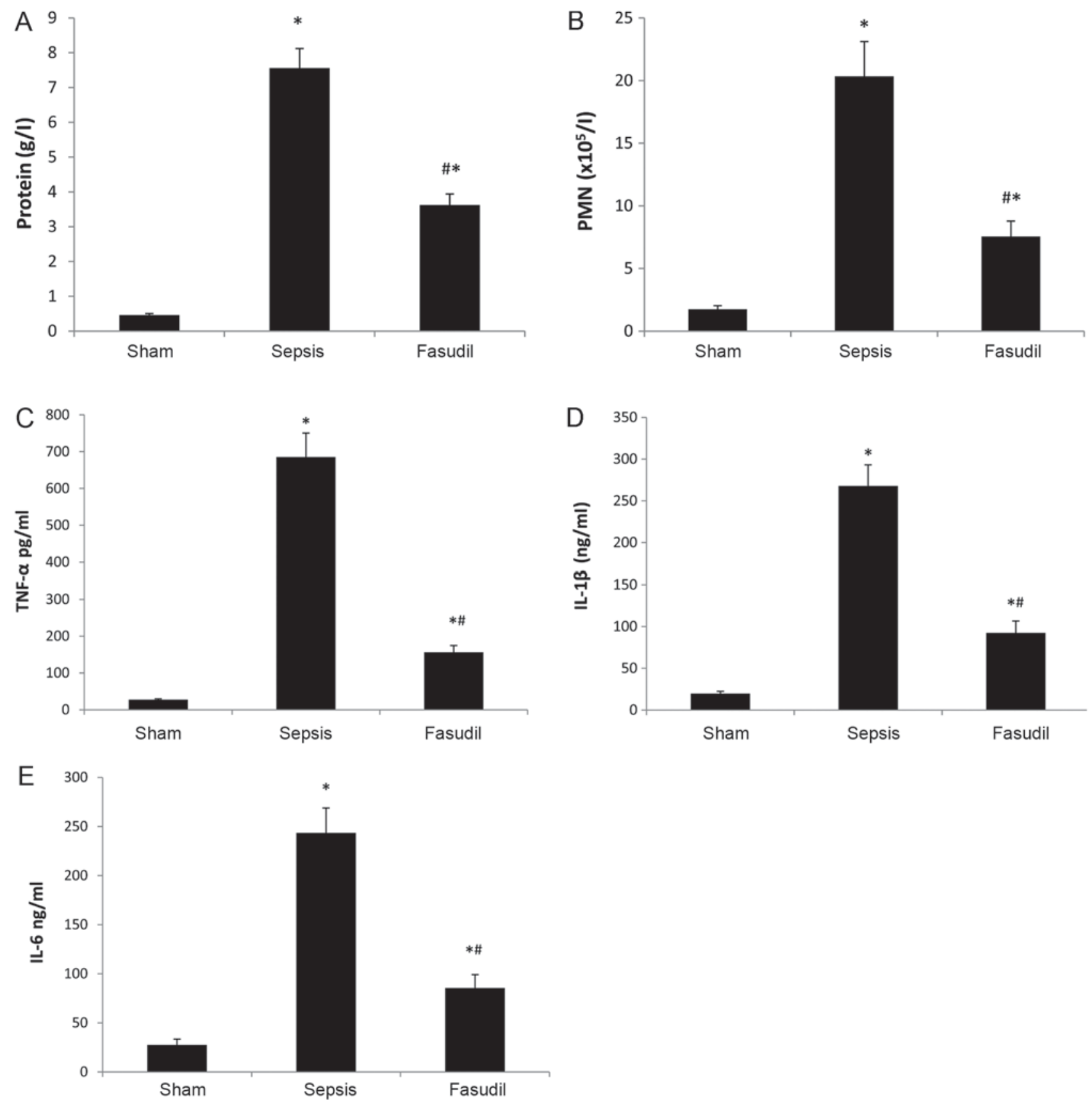

Figure 3. Effect of fasudil on inflammatory biomarkers in the bronchoalveolar lavage fluid in rats with sepsis-induced ALI. Fasudil decreased the concentrations of (A) protein, (B) PMN counts, and (C) TNF- $\alpha$, (D) IL-1 $\beta$ and (E) IL-6 levels in the bronchoalveolar lavage fluid of rats with sepsis-induced ALI. Data are expressed as the mean \pm standard deviation. $\mathrm{n}=10$. " $\mathrm{P}<0.05$ vs. Sham; ${ }^{*} \mathrm{P}<0.05$ vs. Sepsis. ALI, acute lung injury; PMN, polymorphonuclear neutrophils; TNF- $\alpha$, tumor necrosis factor $\alpha$; IL interleukin.

group, yet the activity of SOD was significantly increased $(\mathrm{P}<0.05 ; \mathrm{n}=10$; Fig. 2B-D).

W/D lung weight ratios. W/D weight ratios in the sepsis group were significantly increased compared with the sham-operated group; however, the ratios in the fasudil group were significantly decreased compared with the sepsis group $(\mathrm{P}<0.05$; $\mathrm{n}=10$; Fig. 2E).

$B A L F$ indexes. Compared with the sham-operated group, PMN counts and the total protein content, TNF- $\alpha$, IL- $1 \beta$ and IL-6 in the BALF were significantly increased in the sepsis group. Conversely, all of these indices in the fasudil group were significantly reduced compared with the sepsis group $(\mathrm{P}<0.05$; $\mathrm{n}=10$; Fig. 3). Furthermore, the concentrations of TNF- $\alpha$, IL-1 $\beta$ and IL- 6 in the sepsis group were $685.3 \pm 65.3 \mathrm{pg} / \mathrm{ml}$, $267.8 \pm 25.3$ and $243.5 \pm 25.4 \mathrm{ng} / \mathrm{ml}$, respectively; whereas, the concentrations of TNF- $\alpha$, IL- $1 \beta$ and IL- 6 in the fasudil group were $156.4 \pm 18.3 \mathrm{pg} / \mathrm{ml}, 92.4 \pm 14.3$ and $85.4 \pm 13.7 \mathrm{ng} / \mathrm{ml}$. Therefore, fasudil significantly decreased BALF concentrations of TNF- $\alpha$ by $77 \%$, IL- $1 \beta$ by $65 \%$ and IL- 6 by $65 \%$ in CLP-induced ALI.

Pulmonary histopathology. When examined microscopically, the alveolar structure appeared to be intact, the pulmonary interstitium was not notably edematous, and there was no 
A

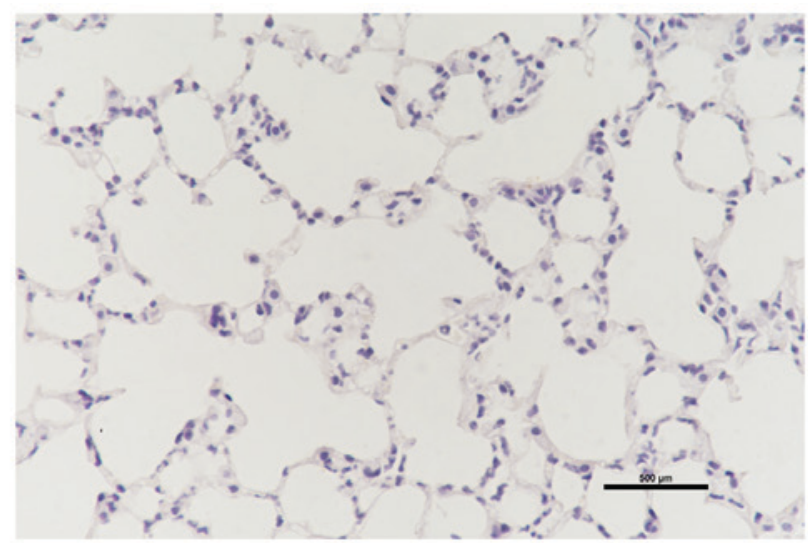

C

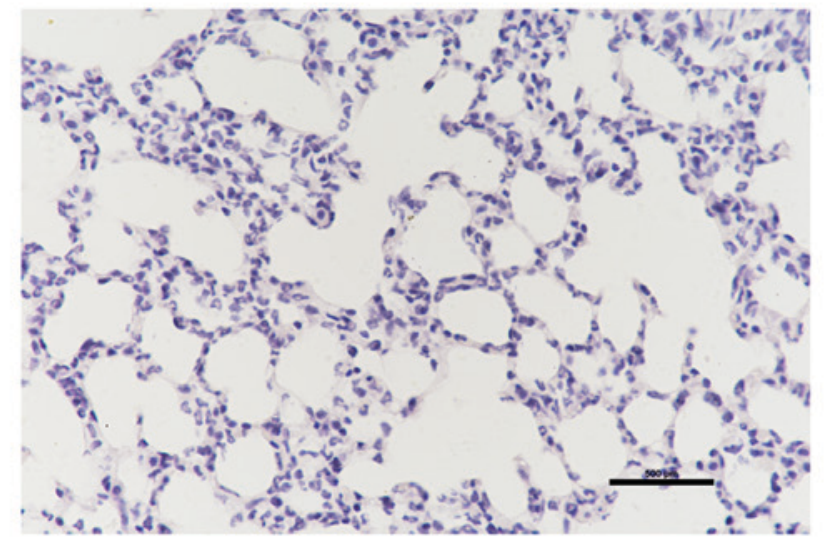

B

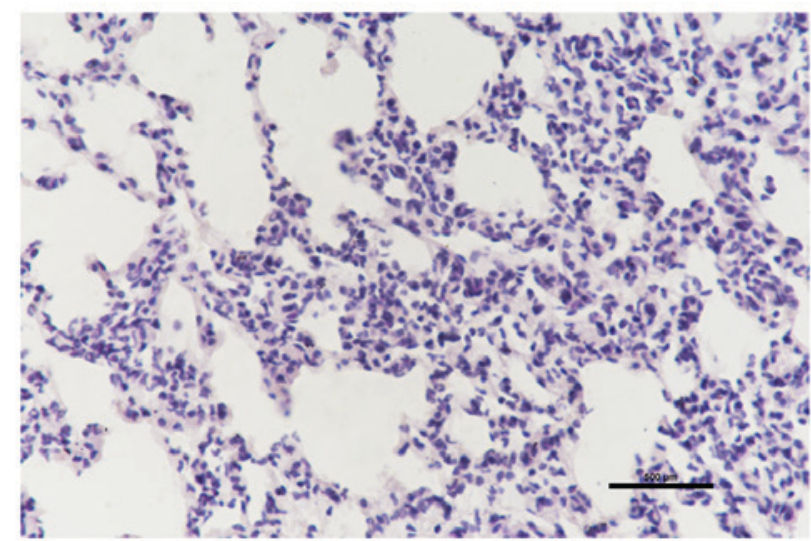

D

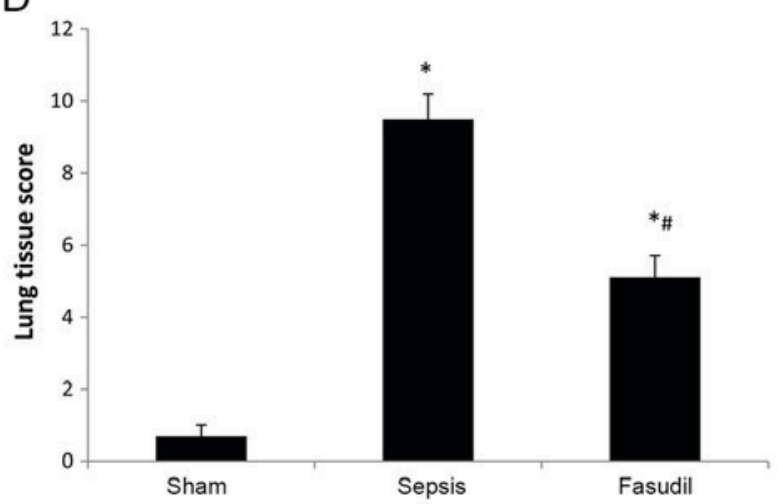

Figure 4. Effect of fasudil on pulmonary histopathology in rats with sepsis-induced ALI. Lung tissues were fixed with 4\% paraformaldehyde, dehydrated, embedded in paraffin, sectioned and stained with hematoxylin and eosin (magnification, $\mathrm{x} 400$ ). Fasudil ameliorated the histopathological damage in the lung tissue of rats with sepsis. (A) sham-operated rat; (B) septic rat; (C) septic rat treated with fasudil; (D) Lung injury scores in the three groups. Data are expressed as the mean \pm standard deviation. $n=10$. ${ }^{*} \mathrm{P}<0.05$ vs. Sham; ${ }^{\#} \mathrm{P}<0.05$ vs. Sepsis. ALI, acute lung injury.

evidence of inflammatory cell infiltration in the sham-operated group. Conversely, lung tissues from the sepsis group were severely damaged. Interstitial congestion, edema and thickening of alveolar wall, in addition to large numbers of inflammatory cells, were observed. Lung tissue injuries in the fasudil group were significantly less severe compared with the sepsis group (Fig. 4A-C). Furthermore, lung injury scores in the fasudil group were significantly lower compared with the sepsis group $(\mathrm{P}<0.05$; Fig. 4D).

Caspase- 3 activity in lung tissue. The caspase- 3 activity in the lung tissue was 0.13 in the sham operation group; however, in the sepsis group, the proportion increased to 0.61 . When compared with the sepsis group, in the fasudil group the caspase-3 activity in the lung tissue was decreased to 0.29 $(\mathrm{P}<0.05 ; \mathrm{n}=10$; Fig. 5A).

Expression of Rho, ROCK1, MYPT-1 and p-MYPT-1 in lung tissue. Compared with the sham group, the expression of Rho and ROCKl was significantly upregulated, and the phosphorylation of MYPT-1 in the lung tissues was significantly increased in the sepsis group $(\mathrm{P}<0.05)$. However, when compared with the sepsis group, the expression of Rho and ROCKl in lung tissues was significantly downregulated, and the phosphorylation of MYPT-1 in lung tissues was significantly decreased in the fasudil group ( $\mathrm{P}<0.05$; Fig. 5B).
Protein expression levels of $\mathrm{ZO}-1$ in the lung tissue. Compared with the sham group, the protein expression levels of ZO-1 were decreased in the sepsis group, whereas the protein expression levels of ZO-1 increased in the fasudil group $(\mathrm{P}<0.05$; Fig. 5C).

Effects of LPS on the growth of HPMVEC-ST1.6R cells and the intervention effect of fasudil. To analyze the effect of LPS on the viability of HPMVEC-ST1.6R, the cells were exposed to different concentrations of LPS for $24 \mathrm{~h}$. The results of the MTT assay indicated that LPS significantly reduced the viability of HPMVEC-ST1.6R in a dose-dependent manner (Fig. 6A). The results demonstrated that compared with the control group, $0.01,0.1$ and $1 \mu \mathrm{g} / \mathrm{ml}$ LPS had no apparent effect on HPMVEC-ST1.6R growth; whereas, 10 and $100 \mu \mathrm{g} / \mathrm{ml}$ LPS significantly inhibited HPMVEC-ST1.6R growth, and the OD values were reduced to $0.754 \pm 0.19$ and $0.50 \pm 0.12$ respectively. From the above results, it appeared that $10 \mu \mathrm{g} / \mathrm{ml}$ LPS may affect the growth of HPMVEC-ST1.6R without causing too much damage. There remained enough cells for the subsequent experiments. Therefore, $10 \mu \mathrm{g} / \mathrm{ml}$ LPS was selected to generate HPMVEC-ST1.6R damage models. The results of the present study were similar to those of a previous study (10). Pretreatment with either 25 or $50 \mu \mathrm{M}$ fasudil was demonstrated to alleviate the cell damage induced by LPS for $24 \mathrm{~h}$ $(\mathrm{P}<0.05$ vs. LPS group; Fig. 6B). 


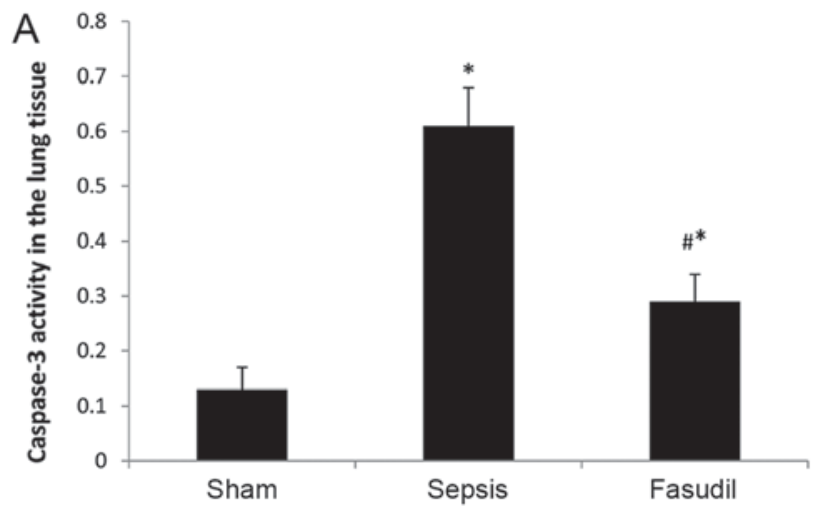

B

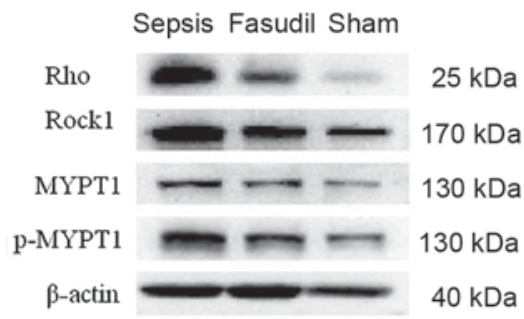

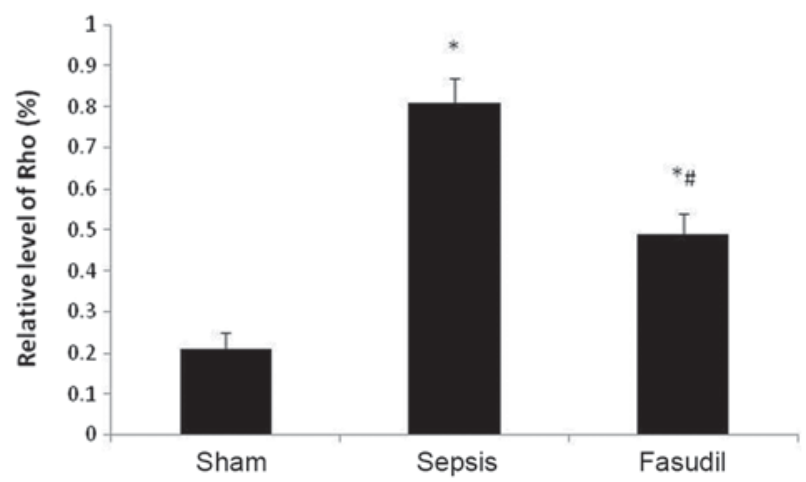
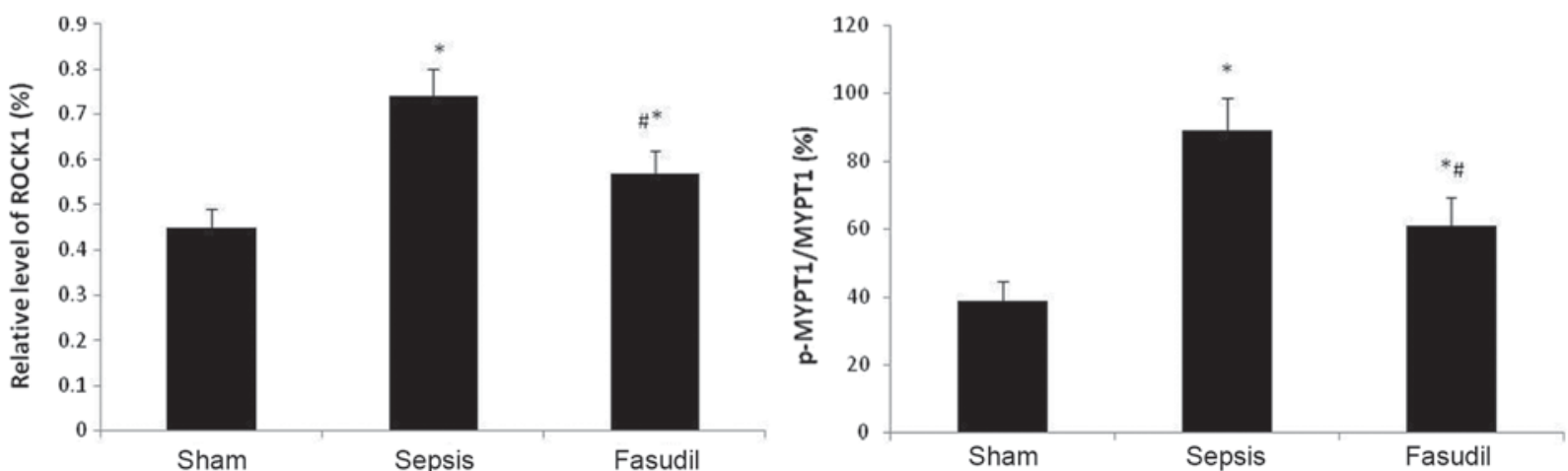

C
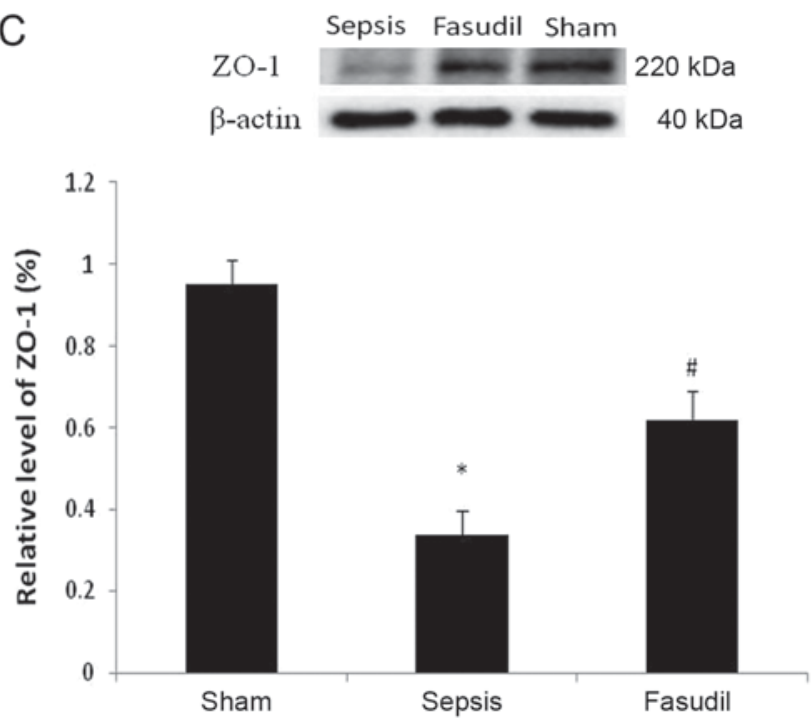

Figure 5. Effect of fasudil on the caspase-3 activity and Rho/ROCK1 signaling pathway in rats with sepsis-induced ALI. (A) Fasudil decreased the percentage caspase-3 activity in rats with sepsis-induced ALI. (B) Fasudil significantly downregulated the expression of Rho and ROCK1, and decreased the phosphorylation of MYPT-1 in rats with sepsis-induced ALI. (C) Fasudil significantly increased the protein expression levels of ZO-1. Data are expressed as the mean \pm standard deviation. $n=10$. ${ }^{*} \mathrm{P}<0.05$ vs. Sham; ${ }^{*} \mathrm{P}<0.05$ vs. Sepsis. ALI, acute lung injury; MYPT-1, myosin phosphatase targeting subunit $1 ; \mathrm{ZO}-1$, zonula occludens 1; Rho, rhodopsin; ROCK1, Rho-associated protein kinase; $p$, phosphorylated. 

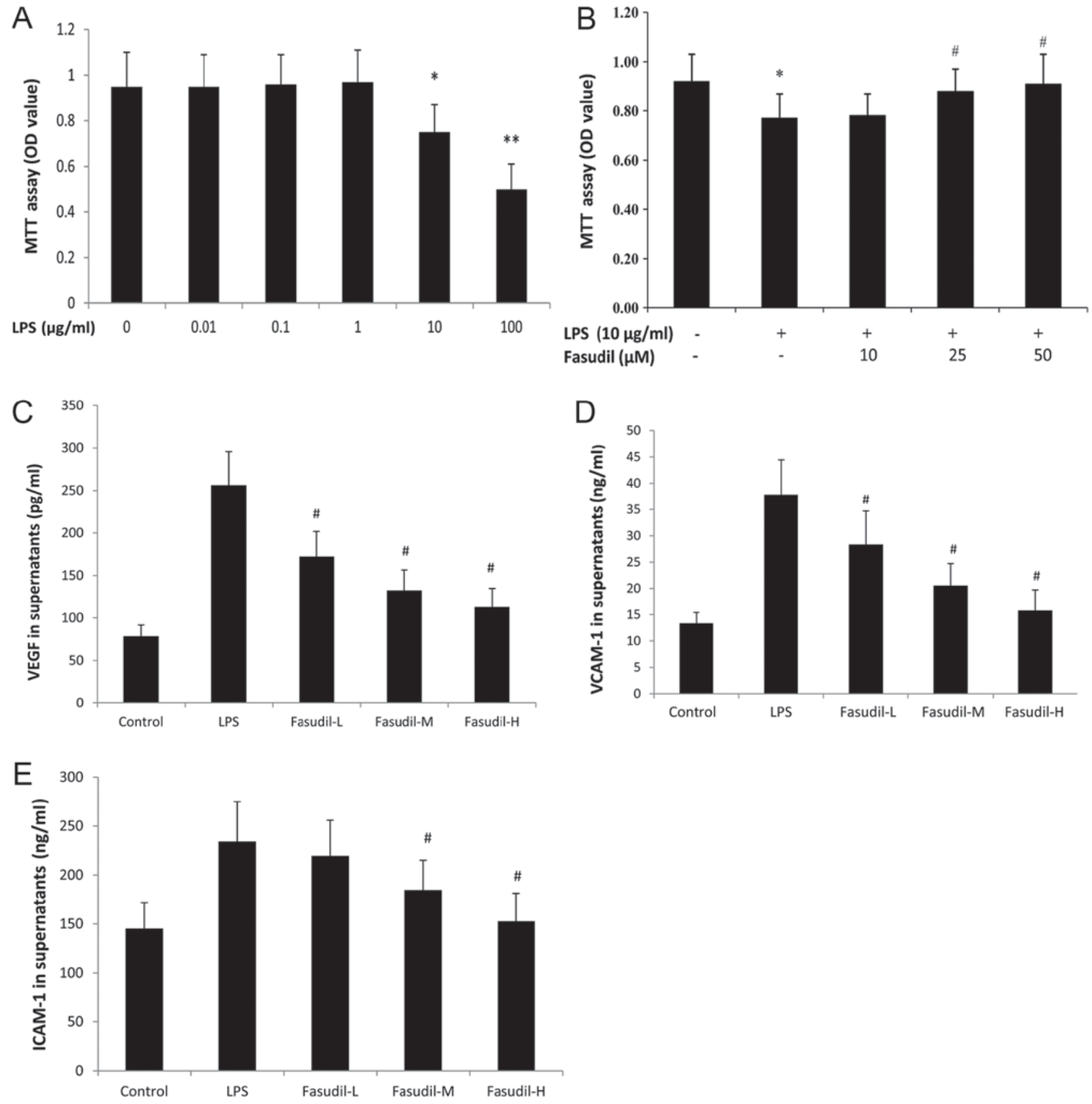

Figure 6. Effect of fasudil on the viability and the secretion of inflammatory cytokines from HPMVEC-ST1.6R treated with LPS. (A) The effect of LPS on the viability of HPMVEC-ST1.6R was examined by MTT assay. $n=6$. ${ }^{*} \mathrm{P}<0.05,{ }^{* * *} \mathrm{P}<0.01$, vs. control. (B) Fasudil relieved the cytotoxic effects of LPS on rat HPMVEC- ST1.6R examined by MTT assay. Data are expressed as the mean \pm standard deviation. $n=6$. ${ }^{*} \mathrm{P}<0.05$ vs. control group; ${ }^{\#} \mathrm{P}<0.05$ vs. LPS-only group. Fasudil inhibited LPS-induced (C) VEGF, (D) ICAM-1 and (E) VCAM-1 secretion from HPMVEC-ST1.6R. Fasudil (10, 25 and $50 \mu \mathrm{M}$ ) was separately preincubated with HPMVEC-ST1.6R 30 min prior to LPS exposure. Supernatants were detected using ELISA for VEGF, ICAM-1 and VCAM-1. Fasudil-L, fasudil at a concentration of $10 \mu \mathrm{M}$; fasudil-M, fasudil at a concentration of $25 \mu \mathrm{M}$; fasudil-H, fasudil at a concentration of $50 \mu \mathrm{M}$. Data are expressed as the mean \pm standard deviation. $\mathrm{n}=6 .{ }^{~} \mathrm{P}<0.05 \mathrm{vs}$. LPS group. LPS, lipopolysaccharide, VEGF, vascular endothelial growth factor, ICAM-1, intracellular cell adhesion molecule-1; VCAM-1, vascular cell adhesion molecule 1; OD, optical density; HPMVEC, human pulmonary microvascular endothelial cells.

VEGF, ICAM-1 and VCAM-1 from HPMVEC-ST1.6R treated with LPS are weakened by fasudil. To confirm whether fasudil acted on the secretion of VEGF, ICAM-1 and VCAM-1 from HPMVEC-ST1.6R, HPMVEC-ST1.6R exposed to LPS were pretreated with different concentrations of fasudil. Fasudil at high concentrations $(25$ and $50 \mu \mathrm{M})$ significantly reduced VEGF, ICAM-1 and VCAM-1 levels in the supernatant of HPMVEC-ST1.6R in a dose-dependent manner (Fig. 6C-E).
Effect of fasudil on the distribution of F-actin in HPMVEC-ST1.6R skeletal actin. In the control group, a small amount of F-actin was observed and was predominantly distributed around the cells with a clear border. It was demonstrated that the F-actin around the cells gradually decreased following $24 \mathrm{~h}$ of treatment with $10 \mu \mathrm{g} / \mathrm{ml}$ LPS. Densely-bunched stress fibers were observed in the cytoplasm. F-actin appeared to exhibit a scattered distribution, and the normal junctions between cells were lost. However, in the 


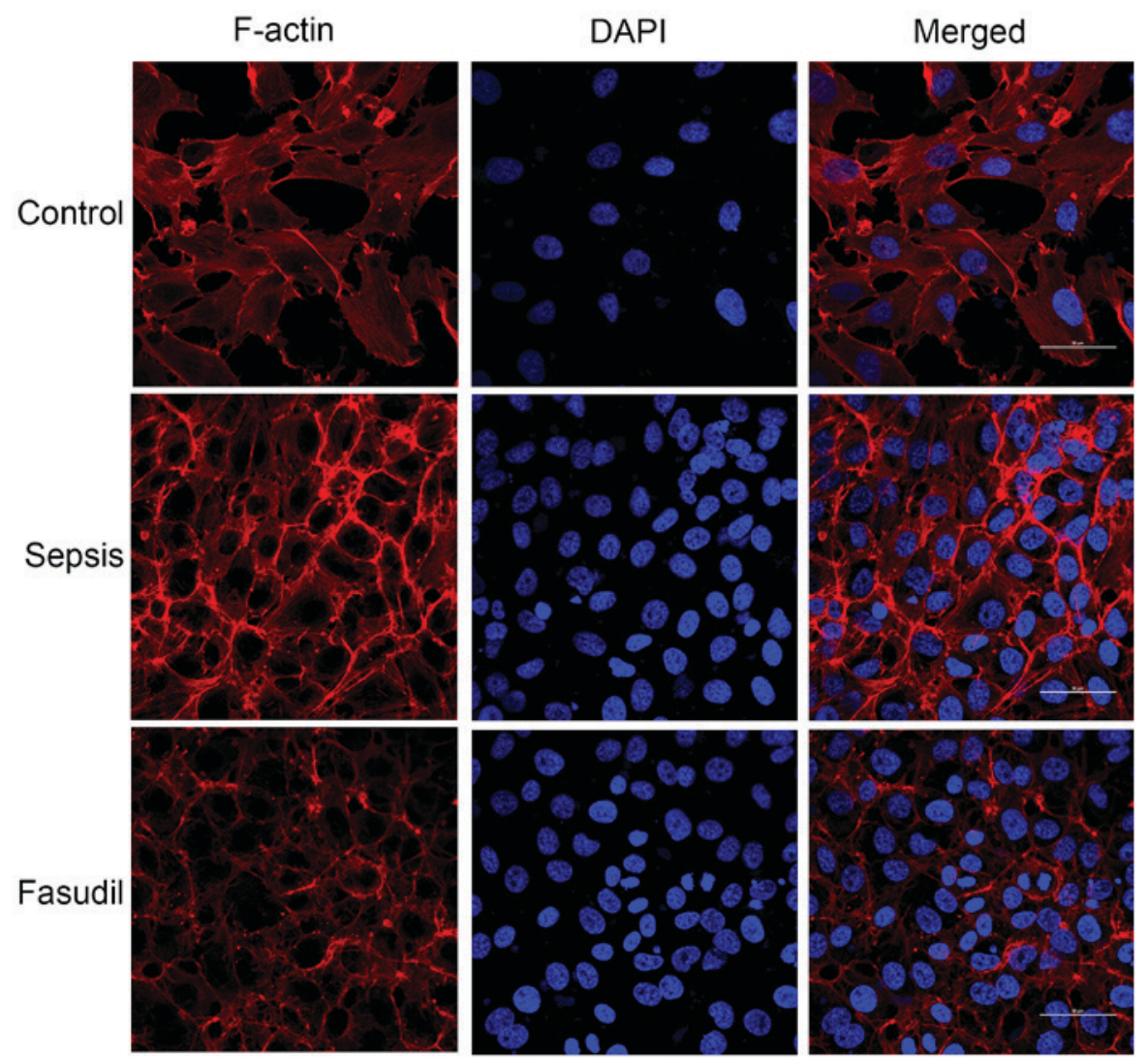

Figure 7. Effect of fasudil on the LPS-induced reorganization of actin filaments in HPMVEC-ST1.6R (magnification, x600). HPMVEC-ST1.6R were pretreated with or without fasudil $(50 \mu \mathrm{M})$ for $2 \mathrm{~h}$, stimulated with LPS $(10 \mu \mathrm{g} / \mathrm{ml})$ for $24 \mathrm{~h}$, and the F-actin stress fibers were stained with fluorescein isothiocyanate-conjugated phalloidin and visualized by confocal microscopy. Fasudil prevented the LPS-induced reorganization of actin filaments. LPS, lipopolysaccharide; HPMVEC, human pulmonary microvascular endothelial cells; F-actin, filamentous actin.

cells pretreated with the ROCK inhibitor fasudil $(50 \mu \mathrm{M})$, the formation of HPMVEC stress fibers and alterations in the cytoskeletal morphology were partially inhibited. The fluorescence intensity and the expression of F-actin were also markedly decreased (Fig. 7), indicating that fasudil may inhibit LPS-induced morphological and cytoskeletal alterations in HPMVECs.

\section{Discussion}

Sepsis may lead to multiple organ dysfunction syndrome and multiple organ failure, among which ALI is the most common organ injury (11). Alveolar endothelial cell damage is a principal mechanism of ALI. Once damaged, endothelial cells exhibit trans-endothelial fluid transport, taking advantage of disordered cell-gap formation, causing inflammatory cell infiltration and resulting in pulmonary edema and lung parenchymal injury, which are associated with pulmonary dysfunction (12). Early identification and early treatment of sepsis/septic shock may improve the prognosis and reduce the mortality associated with sepsis (13). Certain patients with appendicitis, with a history of abdominal pain for less than $24 \mathrm{~h}$, abdominal local pressure pain and hemodynamic stability, may be treated non-surgically (14). However, others with appendicitis are advised to undergo surgery within $24 \mathrm{~h}$ of symptom onset so as to reduce the risk of complications (15). With or without shock, patients with severe sepsis required treatment as early as possible (16). Based on these considerations, fasudil was administered $1 \mathrm{~h}$ prior to CLP in the present study. In addition, the dose of fasudil $(30 \mathrm{mg} / \mathrm{kg})$ was determined based on previous research $(17,18)$, in addition to pharmacological and toxicological profile of fasudil. The present study aimed to investigate the pharmacological effects of fasudil on ALI in septic rats. The results of the present study demonstrated that the EB content and the protein levels in the BALF increased in CLP-induced septic rats, suggesting that the permeability of the endothelial cells had increased. The levels of bacteria in the blood increased, in addition to the concentrations of TNF- $\alpha$, IL- $1 \beta$ and IL- 6 in the BALF, accompanied by a large number of PMN and an augmentation of MDA and MPO levels. However, a decrease in SOD activity was observed. The expression of activated caspase-3 was upregulated in septic rats. These results indicated that the lung tissue exhibited a marked inflammatory reaction, inducing oxidative stress and apoptosis, leading to pulmonary edema and lung parenchymal injury. Treatment with fasudil inhibited the increase in lung endothelial cell permeability, inflammatory response, oxidative stress and apoptosis, thereby reducing pulmonary edema and lung parenchymal injury, demonstrating that fasudil had a protective effect against lung injury in septic rats with ALI.

Rho is a $G$ protein that cycles between an inactive GDP-bound and an active GTP-bound state, and serves an important role in cell adhesion, contraction, movement and division by combining with its downstream target molecules (19). ROCK is a major downstream signaling molecule 
of Rho with two subtypes, ROCK1 and ROCK2. ROCK is distributed in tissues throughout the body. ROCK1 is principally expressed in non-neural tissues, including the liver, lungs, spleen and testes; however, ROCK 2 exhibits increased expression in the brain, heart and muscles. MYPT-1 acts as the principal downstream effector protein of ROCK, whose phosphorylation level may indirectly reflect the activity of ROCK (20). Rho may be activated by histamine, thrombin, VEGF, LPS and mechanical action. Activated Rho binds to ROCK and may increase calmodulin formation, upregulate the concentration of intracellular $\mathrm{Ca}^{2+}$, and activate and induce the phosphorylation of MYPT-1, which inhibits the activity of myosin light chain phosphatase, causing myosin light chain phosphorylation. The phosphorylation of myosin light chain results in myosin contraction, cytoskeletal remodeling, and the abnormal expression and distribution of intercellular tight junction proteins including ZO-1, which eventually leads to endothelial cell permeability enhancement and a deficiency in barrier function (21-23). Caspase-3 is the most important terminal cleavage enzyme in the process of apoptosis. Caspase-3 can induce a conformational change in ROCK-1 during apoptosis, which leads to a persistent activation state of ROCK-1 $(24,25)$. The results of the present study demonstrated that the expression of Rho and ROCK1 was downregulated and the phosphorylation level of MYPT-1 in the lung tissue was decreased in the group treated with fasudil. Furthermore, as an indicator of endothelial integrity and ROCK-targeting, the expression of ZO-1 was upregulated in the group treated with fasudil. Fasudil also prevented the LPS-induced reorganization of actin filaments in vitro. This suggested that the mechanism of action of fasudil in alleviating oxidative stress, and reducing the inflammatory response and apoptosis in septic rats with ALI, was associated with inhibition of the Rho/ROCK pathway. Rho/ROCK pathway targeted therapy has been used in clinical disease and has achieved positive results (26-28).

PMVECs, important parenchymal cells in lung tissue, are an important target of inflammation and a source of inflammatory reactions, which may be activated to produce a number of inflammatory mediators, including IL-6, IL-8, TNF- $\alpha$ and cellular chemokines, including ICAM-1 and VCAM-1. These inflammatory mediators are able to directly move into the blood vessels and alveolar cavity or indirectly move through the recruitment of other inflammatory cells, thereby increasing the endothelial cells and the surrounding tissue damage induced by pathological alterations in ALI (29). Therefore, damage to pulmonary endothelial cells, particularly microvascular endothelial cells, has been regarded as one of the characteristics of ALI. As a strong inflammatory response promoter, LPS is the key initiator of endothelial dysfunction in sepsis (30). LPS may directly act on PMVECs, resulting in apoptosis, cytoskeletal rearrangement, permeability enhancement and inflammatory cytokine release (31). Therefore, the present study aimed to examine the effect of fasudil on the expression of HPMVE inflammatory factors in an LPS-induced HPMVEC injury model.

VEGF is known as the most active substance in promoting vascular permeability in vivo, and is primarily expressed by alveolar type II epithelial cells. When the epithelial barrier of the lung is damaged, VEGF may increase vascular permeability, which eventually leads to pulmonary edema. The expression of VEGF protein in the lung tissue of rats with sepsis was significantly increased (32). ICAM-1 and VCAM-1 belong to the adhesion molecule immunoglobulin superfamily. A small amount of ICAM-1 was expressed in pulmonary vascular endothelial cells in a normal physiological environment, while it was overexpressed in sepsis. The necrosis and apoptosis of pulmonary vascular endothelial cells in rats is associated with the overexpression of ICAM-1 (33).

VCAM-1 is a neutrophil surface adhesion molecule-integrin ligand, which serves an important role in the adhesion and migration of neutrophils to endothelial cells (34). According to the present results, the levels of VEGF, ICAM-1 and VCAM-1 secreted by HPMVECs were significantly increased following LPS stimulation. Following intervention with fasudil, the levels of VEGF, ICAM-1 and VCAM-1 secreted by HPMVECs were significantly decreased in a dose-dependent manner. In vitro experiments also confirmed that fasudil downregulated the expression of associated adhesion molecules and improved pulmonary capillary permeability induced by CLP.

Fasudil dilates blood vessels by inhibiting the final stage of smooth muscle contraction via the phosphorylation of myosin light chains (35), causing hypotension and reflex tachycardia. According to the results of the present study, MAP was increased in the fasudil group compared with the sepsis group, whereas the difference in heart rate between the three groups was not statistically significant. It was hypothesized that fasudil has a protective effect on lung injury in sepsis, and also is not associated with any serious adverse reactions. The present study provided a theoretical basis for the use of fasudil in the clinical treatment of sepsis. However, only a single dose of fasudil was given at one time point in the present study, which may limit the possibility for clinical extrapolation.

A previous study demonstrated that pretreatment with the ROCK inhibitor Y-27632 markedly reduced the LPS-induced expression of IL-1 $\beta$ and IL-6, and the activation of nuclear factor $(\mathrm{NF})-\kappa \mathrm{B}$. Furthermore, ROCK inhibitor treatment antagonized the expression of tissue factor and plasminogen activator inhibitor-1 in lung tissue and HPMVECs. These results suggested the ROCK inhibition protects against endotoxin-induced pulmonary inflammation and coagulation via $\mathrm{NF}-\kappa \mathrm{B}$ pathway modulation (36)

Fasudil, an inhibitor of ROCK which is a commonly used drug in clinical practice, has a wide range of pharmacological effects, and may potentially serve an invaluable role in the prevention and treatment of cardiovascular and cerebrovascular diseases. The clinical application of fasudil in sepsis remains to be further investigated. With an in-depth study of the mechanism of action of ALI, fasudil may become a candidate drug for future ALI treatment.

In summary, the present study demonstrated that treatment with fasudil had a protective effect on lung injury in septic rats. The mechanism may involve fasudil contributing to inhibition of the activity of the Rho/ROCK signaling pathway in lung tissues. Fasudil improved endothelial permeability and reduced lung inflammation, oxidative stress and apoptosis, thereby reducing lung injury. 


\section{Acknowledgements}

Not applicable.

\section{Funding}

The present study was funded in part by Liaoning Science and Technology Project of China (grant no. 17-230-9-58).

\section{Availability of data and materials}

All data generated and/or analyzed during this study are included in this published article.

\section{Authors' contributions}

YW contributed to conceiving and designing the experiment, analysis and interpretation of data, manuscript preparation and critical evaluation. XW contributed to experimental studies, data interpretation, statistical analysis and manuscript preparation. WL and LZ contributed to experimental studies, data interpretation and statistical analysis. All authors reviewed the manuscript.

\section{Ethics approval and consent to participate}

All experimental protocols were conducted with the approval of the Medical Research and New Technology Ethics Committee of Shengjing Hospital affiliated to China Medical University.

\section{Patient consent for publication}

Not applicable.

\section{Competing interests}

The authors declare that they have no competing interests.

\section{References}

1. Bastarache JA, Ware LB and Bernard GR: The role of the coagulation cascade in the continuum of sepsis and acute lung injury and acute respiratory distress syndrome. Semin Respir Crit Care Med 27: 365-376, 2006.

2. Eiznhamer DA, Flavin MT, Jesmok GJ, Borgia JF, Nelson DJ, Burhop KE and Xu ZQ: Effective attenuation of endotoxin-induced acute lung injury by 2,3-diacetyloxybenzoic acid in two independent animal models. Pulm Pharmacol Ther 17: 105-110, 2004.

3. Amin E, Dubey BN, Zhang SC, Gremer L, Dvorsky R, Moll JM, Taha MS, Nagel-Steger L, Piekorz RP, Somlyo AV and Ahmadian MR: Rho-kinase: Regulation, (dys)function, and inhibition. Biol Chem 394: 1399-1410, 2013.

4. Cinel I, Ark M, Dellinger P, Karabacak T, Tamer L, Cinel L, Michael P, Hussein S, Parrillo JE, Kumar A and Kumar A: Involvement of Rho kinase (ROCK) in sepsis-induced acute lung injury. J Thorac Dis 4: 30-39, 2012.

5. Ding RY,Zhao DM,Zhang ZD, Guo RX and Ma XC: Pretreatment of Rho kinase inhibitor inhibits systemic inflammation and prevents endotoxin-induced acute lung injury in mice. J Surg Res 171: e209-e214, 2011.

6. Rittirsch D, Huber-Lang MS, Flierl MA and Ward PA: Immunodesign of experimental sepsis by cecal ligation and puncture. Nat Protoc 4: 31-36, 2009.

7. Han J, Ding R, Zhao D, Zhang Z and Ma X: Unfractionated heparin attenuates lung vascular leak in a mouse model of sepsis: Role of RhoA/Rho kinase pathway. Thromb Res 132: e42-e47, 2013.
8. Wu R, Dong W, Zhou M, Zhang F, Marini CP, Ravikumar TS and Wang P: Ghrelin attenuates sepsis-induced acute lung injury and mortality in rats. Am J Respir Crit Care Med 176: 805-813, 2007.

9. Kim I, Kim HG, So JN, Kim JH, Kwak HJ and Koh GY: Angiopoietin-1 regulates endothelial cell survival through the phosphatidylinositol 3'-kinase/Akt signal transduction pathway. Circ Res 86: 24-29, 2000.

10. Li C, Ma D, Chen M, Zhang L, Zhang L, Zhang J, Qu X and Wang C: Ulinastatin attenuates LPS-induced human endothelial cells oxidative damage through suppressing JNK/c-Jun signaling pathway. Biochem Biophys Res Commun 474: 572-578, 2016.

11. Angus DC and van der Poll T: Severe sepsis and septic shock. N Engl J Med 369: 840-851, 2013.

12. Tasaka S, Koh H, Yamada W, Shimizu M, Ogawa Y, Hasegawa N, Yamaguchi K, Ishii Y, Richer SE, Doerschuk CM and Ishizaka A: Attenuation of endotoxin-induced acute lung injury by the Rho-associated kinase inhibitor, Y-27632. Am J Respir Cell Mol Biol 32: 504-510, 2005.

13. Moore LJ and Moore FA: Early diagnosis and evidence-based care of surgical sepsis. J Intensive Care Med 28: 107-117, 2013.

14. Abes M, Petik B and Kazil S: Nonoperative treatment of acute appendicitis in children. J Pediatr Surg 42: 1439-1442, 2007.

15. Kim M, Kim SJ and Cho HJ: Effect of surgical timing and outcomes for appendicitis severity. Ann Surg Treat Res 91: 85-89, 2016.

16. Ferrer R, Martin-Loeches I, Phillips G, Osborn TM, Townsend S, Dellinger RP, Artigas A, Schorr C and Levy MM: Empiric antibiotic treatment reduces mortality in severe sepsis and septic shock from the first hour: Results from a guideline-based performance improvement program. Crit Care Med 42: 1749-1755, 2014.

17. Thorlacius K, Slotta JE, Laschke MW, Wang Y, Menger MD, Jeppsson B and Thorlacius H: Proective effect of fasudil, a Rho-kinase inhibitor, on chemokine expression, leukocyte recruitment, and hepatocellular apoptosis in septic liver injury. J Leukoc Biol 79: 923-931, 2006.

18. Preau S, Delguste F, Yu Y, Remy-Jouet I, Richard V, Saulnier F, Boulanger E and Neviere R: Endotoxemia engages the RhoA kinase pathway to impair cardiac function by altering cytoskeleton, mitochondrial fission and autophagy. Antioxid Redox Signal 24: 529-542, 2016.

19. Wojciak-Stothard B and Ridley AJ: Rho GTPases and the regulation of endothelial permeability. Vascul Pharmaeol 39: 187-199, 2002.

20. Ma T, Liu L, Wang P and Xue Y: Evidence for involvement of ROCK signaling in bradykinin-induced increase in murine blood-tumor barrier permeability. J Neurooncol 106: 291-301, 2012.

21. Chen SC, Liu CC, Huang SY and Chiou SJ: Vascular hyperpermeability in response to inflammatory mustard oil is mediated by Rho kinase in mice systemically exposed to arsenic. Microvasc Res 82: 182-189, 2011.

22. Yu Y, Qin J, Liu M, Ruan Q, Li Y and Zhang Z: Role of Rho kinase in lysophosphatidic acid-induced altering of blood-brain barrier permeability. Int J Mol Med 33: 661-669, 2014.

23. Bogatcheva NV, Zemskova MA, Poirier C, Mirzapoiazova T, Kolosova I, Bresnick AR and Verin AD: The suppression of myosin light chain (MLC) phosphorylation during the response to lipopolysaccharide (LPS): Beneficial or detrimental to endothelial barrier. J Cell Physiol 226: 3132-3146, 2011.

24. Chen LW, Chen W, Hu ZQ, Bian JL, Ying L, Hong GL, Qiu QM, Zhao GJ and Lu ZQ: Protective effects of growth arrest-specific protein 6 (Gas6) on sepsis-induced acute kidney injury. Inflammation 39: 575-582, 2016.

25. Bessho M, Aki T, Funakoshi T, Unuma K, Noritake K, Kato C and Uemura K: Rho-kinase inhibitor Y-27632 attenuates arsenic trioxide toxicity in H9c2 cardiomyoblastoma cells. Cardiovasc Toxicol 13: 267-277, 2013.

26. Nozaki Y, Kinoshita K, Hino S, Yano T, Niki K, Hirooka Y, Kishimoto K, Funauchi M and Matsumura I: Signaling Rho-kinase mediates inflammation and apoptosis in T cells and renal tubules in cisplatin nephrotoxicity. Am J Physiol Renal Physiol 308: F899-F909, 2015.

27. Kohno M, Watanabe M, Goto T,Kamiyama I, Ohtsuka T, Tasaka S and Sawafuji M: Attenuation of lung ischemia-reperfusion injury by rho-associated kinase inhibition in a rat model of lung transplantation. Ann Thorac Cardiovasc Surg 20: 359-364, 2014. 
28. Shen W, Wang L, Pi R, Li Z and Rikang Wang: L-F001, a multifunctional ROCK inhibitor prevents paraquat-induced cell death through attenuating ER stress and mitochondrial dysfunction in PC12 cells. Biochem Biophys Res Commun 464: 794-799, 2015.

29. Chen H, Bai C and Wang X: The value of the lipopolysaccharide-induced acute lung injury model in respiratory medicine. Expert Rev Respir Med 4: 773-783, 2010.

30. Yang Y, Li Q, Deng Z, Zhang Z, Xu J, Qian G and Wang G: Protection from lipopolysaccharide-induced pulmonary microvascular endothelial cell injury by activation of hedgehog signaling pathway. Mol Biol Rep 38: 3615-3622, 2011.

31. Mizumura K, Gon Y, Kumasawa F, Onose A, Maruoka S, Matsumoto K, Hayashi S, Kobayashi T and Hashimoto S: Apoptosis signal-regulating kinase 1-mediated signaling pathway regulates lipopolysaccharide-induced tissue factor expression in pulmonary microvasculature. Int Immunopharmacol 10: 1062-1067, 2010

32. Liu H, Ren JG, Cooper WL, Hawkins CE, Cowan MR and Tong PY: Identification of the antivasopermeability effect of pigment epithelium-derived factor and its active site. Proc Natl Acad Sci USA 101: 6605-6610, 2004.
33. Kim I, Moon SO, Kim SH, Kim HJ, Koh YS and Koh GY: Vascular endothelial growth factor expression of intercellular adhesion molecule 1 (ICAM-1), vascular cell adhesion molecule 1 (VCAM-1), and E-selectin through nuclear factor-kappa B activation in endothelial cells. J Biol Chem 276: 7614-7620,2001.

34. Jersmann HP, Hii CS, Ferrante JV and Ferrante A: Bacterial lipopolysaccharide and tumor necrosis factor alpha synergistically increase expression of human endothelial adhesion molecules through activation of NF-kappaB and p38 mitogen-activated protein kinase signaling pathways. Infect Immun 69: 1273-1279, 2001.

35. Somlyo AP and Somlyo AV: $\mathrm{Ca}^{2}{ }^{+}$sensitivity of smooth muscle and nonmuscle myosinII: Modulated by $\mathrm{G}$ proteins, kinases, and myosin phosphatase. Physiol Rev 83: 1325-1358, 2003.

36. Ding R, Zhao D, Li X, Liu B and Ma X: Rho-kinase inhibitor treatment prevents pulmonary inflammation and coagulation in lipopolysaccharide-induced lung injury. Thromb Res 150: 59-64, 2017. Attribution 4.0 International (CC BY-NC 4.0) License 